APRESENTAÇÃO 


\section{ROMANCE GRÁFICO E HISPANISMO}

A produção e circulação de romances gráficos em castelhano tem se intensificado nos últimos anos. Para além da adaptação para quadrinhos de obras da tradição literária, romances gráficos autorais sobre os mais variados temas vêm ganhando cada vez mais espaço nas prateleiras das livrarias, tanto na Espanha quanto nos países hispano-americanos. Essa nova forma de produção e veiculação das histórias em quadrinhos contempla hoje novos públicos leitores e, nas Universidades, pesquisadores de diferentes áreas do conhecimento têm se interessado por esse tipo de produção, o que tem estimulado a criação de novas linhas de pesquisa interdisciplinares e a realização de colóquios e congressos destinados especificamente ao tema.

Neste número de Caracol publicam-se dez artigos no dossiê temático, quatro artigos na sessão vária, três entrevistas e duas resenhas, num total de dezenove textos enviados por pesquisadores e professores de quatro universidades brasileiras - Universidade Federal de São Paulo, Universidade de Campinas, Universidade Federal de Minas Gerais e Universidade Federal de Alagoas - e de onze universidades estrangeiras: Universidade ClermontAuvergne (França), Universidade Católica de Milão (Itália), Universidade Nacional de la Plata (Argentina), Universidad de Buenos Aires (Argentina), Unversidad Nacional de Córdoba (Argentina), Universidade Nacional do Nordeste (Argentina), Universidade Nacional do Rio Negro (Argentina), Faculdade de Ciências Sociais de Ljubljana (Eslovenia), Universidade de Massachusetts (EUA), Universidade Autónoma de Barcelona (Espanha) e Universidade de Zaragoza (Espanha). A pluralidade de vozes oriundas 
de diferentes espaços acadêmicos comprova a consolidaçáo do romance gráfico como forma de expressão das angústias e dos desejos de nosso tempo, assim como objeto de reflexão e de pesquisa.

\section{DOSSIÊ: O ROMANCE GRÁFICO}

O dossiê temático deste número da revista CARACOL está composto por artigos relacionados à produção e à circulação de romances gráficos em castelhano e de romances gráficos produzidos em outros idiomas e que de alguma forma dialogam com o universo hispânico.

No primeiro artigo que compóe o dossiê, La literariedad iconotextual en la novela gráfica hispana: prolegómenos, a pesquisadora Viviane Alary (Universidad Clermont-Aurvergne) apresenta uma discussão sobre o termo "romance gráfico", levando em consideração as especificidades e os limites do contexto hispânico para apresentar o que ela denomina de "literariedad iconotextual". A premissa de que parte Alary para situar o debate sobre a terminologia e a historicidade desse tipo de produçáo na Espanha é a de que "una novela gráfica como obra de arte implica como mínimo, la creación de historias singulares y una total libertad del autor o de los autores en cuanto a los formatos, formas, temas e intrigas y el modo de contar".

$\mathrm{O}$ artigo Significados de la representación histórica en algunas novelas gráficas contemporáneas, assinado pela pesquisadora Francesca Crippa (Universidade Católica de Milāo), estabelece relaçóes entre a produção atual de romances gráficos na Espanha e o compromisso dos artistas 
com o resgate da memória histórica e cultural do país. Para a autora, "la producción contemporánea de narrativa se propone a los lectores en términos de ruptura con los moldes tradicionales, a los que se contrapone la búsqueda de modalidades expresivas inéditas que más se adecuan a la representación de las transformaciones con las que la sociedad posmoderna tiene que enfrentarse."

No artigo Historietas herméticas, aproximación a la tira dibujada desde la obra de E. A. Vigo, Julia Cisneros (Universidade Nacional de Córdoba) traça um panorama detalhado da obra do artista argentino Edgardo Antonio Vigo, a partir de cinco reescrituras de sua produção relacionada aos quadrinhos e conclui que, para ele, "un desarrollo poético sobre géneros considerados menores no implica un lenguaje llano, por el contrario: espera que el espectador participe de manera activa en la propuesta estética, decodificando los mensajes y aportando claves de lectura.”

No artigo Diagnósticos, de Diego Agrimbau e Lucas Varela: A Estética dos Quadrinhos como Forma de Representação de Distúrbios Mentais, Fernando Josefh Queiroz (Universidade Federal de Alagoas) e Laureny Aparercida Lourenço Queiroz da Silva (Universidade Federal de Minas Gerais) analisam de que forma os elementos utilizados na composição dos quadrinhos buscam representar os efeitos das patologias retratadas nos seis contos sobre distúrbios psicológicos que compóem a obra Diagnósticos, dos escritores argentinos Diogo Agrimbau e Lucas Varela. Após analisarem detalhadamente os recursos da linguagem pictórica, a importância do código verbal na constituição do cómic, a perspectiva narrativa, o enquadramento, 
os balôes e a construçáo da noçáo de movimento, os autores concluem que em "Diagnósticos, percebe-se que os elementos constituintes do gênero (...) conseguem se reinventar de forma a ampliar o seu potencial narrativo".

No artigo Mortadelo y Filemón: entre La Mancha y los Alpes Julianos, o pesquisador Santiago Martín Sánchez (Universidade de Ljubljana) analisa as equivalências culturais utilizadas na traduçáo de Mortadelo y Filemón para o esloveno. Partindo do princípio de que o trabalho de traduzir implica estabelecer um diálogo cultural entre países e culturas distintas, o autor considera que a tradutora "ha logrado encontrar equivalencias creativas y satisfactorias para el público esloveno. Y lograr, de esta forma, que la obra maestra de Francisco Ibánez sea leída y apreciada como es debido, es decir, como uno de los grandes maestros del cómic europeo del siglo XX y XXI".

No artigo Pablo de Santis y el policial en la historieta: teoría y práctica, o pesquisador Hernán Maltz (Universidade de Buenos Aires e Universidade Nacional de Lomas de Zamora) analisa a produçáo literária e a produçáo de cómics do escritor argentino Pablo de Santis, assim como sua produção teórica para apresentar a hipótese de que "por un lado (...) el género policial une ambas narrativas pero, por otro, ellas se diferencian en que la literatura se sirve más del policial clásico de enigma, mientras que la historieta se aproxima al policial negro".

No artigo La verdad dibujada. Un análisis de la verosimilitud en el CómicPeriodismo de Joe Sacco, o pesquisador Pablo Iván Lamsacov (Universidade Nacional de Córdoba) analisa romances gráficos que narram acontecimentos históricos recentes, a partir das discussōes sobre verossimilhança realizadas 
por Todorov, Kristeva, Barthes e Eco. Ao longo de seu texto, o autor compara os recursos utilizados pelo fotojornalismo e pelo cómic para responder a algumas perguntas que motivam sua reflexão:” ¿Cómo pueden defender su autenticidad, cómo construyen su verosimilitud, estas representaciones de la realidad mediatizadas a través del dibujo, (...) estas representaciones edificadas con los recursos de un artefacto cultural que, ante el sentido común, remite más al género de la fantasía que al del periodismo?”

No artigo $O$ voo peregrinatório: paternidade, morte e sonhos na obra de Antonio Altarriba, Ana Lúcia Mendes Antônio (Universidade Federal de São Paulo) analisa de que forma a construção de imagens no romance gráfico $E l$ arte de volar, de Antonio Altarriba e Kim, metaforiza os pensamentos e os sentimentos do protagonista, no contexto da Guerra Civil Espanhola e do franquismo. Para tanto, a autora percorre as reflexóes sobre paternidade, morte e sonhos apresentadas por Sêneca, Bergamín, María Zambrano e Freud para demonstrar que "um recurso adotado para a expressividade na obra é, em certos momentos, a construção de imagens metafóricas que, para além da mera descrição por palavras, ilustram de modo simbólico sentimentos e pensamentos do protagonista, sejam de angústia, sejam de solidão, sejam de libertação".

No artigo Una Mirada Comparativa Sobre La Edición y Circulación De Historietas En España y Argentina en el Siglo XXI, o pesquisador Horacio Sebastián Gago (Universidade Nacional de Córdoba) analisa comparativamente as condiçôes de produção e circulação do comic na Espanha e na Argentina nas últimas décadas. Após apresentar um 
panorama detalhado das modificaçóes por que passou a indústria do cómic nos dois países, o autor considera que "ese cambio puede ser simbolizado con la etiqueta novela gráfica, que expresa la tensa relación entre producción/consumo masivos y producción/consumo reducidos a un ámbito intelectual/artístico.”

Em Memoria histórica en viñetas: representaciones de la Guerra Civil Española a través de la narrativa gráfica y los testimonios familiares, Carla Suárez Vega (Universidade de Massachusetts) apresenta uma reflexão sobre a produção de romances gráficos baseados em testemunhos dos que vivenciaram a Guerra Civil Espanhola e os anos de silenciamento imposto pela ditadura franquista. A partir da análise de El arte de volar, de Antonio Alatarriba e Kim, e de Un médico novato, de Sento Llobel, a autora observa de que forma "en los dos relatos el mediador de la historia toma como legítima la narración de su familiar y desde la ficcionalización de sus vidas, ofrece una representación de la guerra desde los ojos de sus protagonistas."

Compóem, ainda, este dossiê temático três entrevistas, concedidas exclusivamente a Caracol. Na primeira delas - Con la novela gráfica, los autores somos los dueños de nuestra obra y pasamos a trabajar dentro de un modo literario. Entrevista a Santiago García - o escritor e pesquisador de cómics discorre sobre a história dos quadrinhos na Espanha e sobre as modificações que houve nos modos de produção e de circulação dos quadrinhos em seu país. Na segunda entrevista - Este mestizaje que bay entre literatura y narración gráfica: entrevista a Sento Llobel y a Elena Uriel - o autor da trilogia Un médico novato, Atrapado en Belchite 
e Vencedor y vencido, insipirada nas memórias do Dr. Pablo Uriel, e a artista plástica Elena Uriel falam do processo de reconstituição histórica na elaboração da obra, contextualizada nos anos da Guerra Civil Espanhola e na consequente ditadura franquista. E na terceira entrevista - La memoria me sirve para intentar comprender el presente: entrevista a Paco Rocao escritor valenciano trata do processo criativo de um romance gráfico e de seu compromisso social com a preservação da memória histórica.

\section{VÁRIA}

Além dos artigos que compóem o dossê temático, este número de Caracol publica quatro artigos e duas resenhas na sessáo Vária. No primeiro deles, Confrontar lo indecible en el cine documental argentino y brasileño. Los casos Urondo y Herzog, a professora e pesquisadora Graciela Foglia (Universidade Federal de São Paulo) analisa e interpreta comparativamente os procedimentos de construção narrativa do documentário argentino Paco Urondo, la palabra justa e do documentário brasileiro Vlado, 30 anos depois. Para a autora, "la muerte violenta es el denominador común. Pero la forma como cada documental se posiciona frente a ella, treinta años después, los diferencia. Uno, V30, propone una explicación y algún consuelo para la muerte; el otro, $\mathrm{PU}$, da constancia y pone en tensión elecciones y resultados."

O segundo artigo da sessão, En el Umbral de la Noche: Dau al Set entre las Vanguardias Históricas y el Arte Nuevo, Sol Enjuanes Puyol (Universidade Autônoma de Barcelona) apresenta uma discussão sobre 
o processo de criação da revista Dau al Set, no contexto das inovaçóes artísticas das primeiras décadas do século XX. Segundo a autora, "a pesar de no poder ser considerada un gran logro de la vanguardia por sus características intrínsecas, Dau al Set adquiere una relevancia sobresaliente por la precariedad del contexto cultural en el que surgió”.

No terceiro artigo, Juan L. Ortiz y el budismo: vacuidad y reescritura del dolor, Fabián Humberto Zampini (Universidade Nacional de Rio Negro) apresenta uma leitura das marcas do budismo zen na obra poética de Juan L. Ortiz. Para o autor, "Ortiz, como el príncipe Siddharta, el primer buda, coloca en el centro de su sistema poético la evidencia de la primera de las cuatro nobles verdades comunicadas por Buda Shakiamuni: la persistencia del dolor dominando la vida de los hombres. No obstante, para el poeta, el dolor humano es un hecho que de ninguna manera tendría una justificación o necesidad natural".

E no último artigo que compóe a sessão Vária, Narrativas com imagens. Cinema, literatura e fotografia, Lucía Caminada Rossetti (Universidade Nacional do Nordeste) e Rodrigo Ribeiro (Universidade Federal do Rio de Janeiro) visitam a obra de Julio Cortázar para responder às perguntas "Como ler a imagem visual junto ao texto verbal como estudos experimentais sobre a cultura? Que narrativas emergem dos interstícios da imagem e da palavra?"

E neste número de Caracol, Julio Andrés Gracia Lana, da Universidade de Zaragoza, apresenta uma resenha da obra La máquina y el mito. En el cine y el cómic, de Gino Frezza, publicada em 2017. 
Esperamos que este número de Caracol, pela variedade de temas relativos à produção e à circulação de romances gráficos que apresenta e pela ampla gama de pesquisadores que reúne, contribua para a divulgação e para a consolidação dos estudos relacionados ao cómic e ao hispanismo.

Ivan Rodrigues Martin (Universidade Federal de São Paulo) Organizador 